\title{
High-frequency return and volatility spillovers among cryptocurrencies
}

\section{Ahmet Sensoy, Thiago Christiano Silva, Shaen Corbet \& Benjamin Miranda Tabak}

To cite this article: Ahmet Sensoy, Thiago Christiano Silva, Shaen Corbet \& Benjamin Miranda Tabak (2021) High-frequency return and volatility spillovers among cryptocurrencies, Applied Economics, 53:37, 4310-4328, DOI: 10.1080/00036846.2021.1899119

To link to this article: https://doi.org/10.1080/00036846.2021.1899119

册 Published online: 22 Mar 2021.

6 Submit your article to this journal

III Article views: 273

Q View related articles $\asymp$

View Crossmark data [ᄌ

Citing articles: 1 View citing articles 


\title{
High-frequency return and volatility spillovers among cryptocurrencies
}

\author{
Ahmet Sensoy ${ }^{a}$, Thiago Christiano Silva $\mathbb{I}^{\mathrm{b}, \mathrm{c}}$, Shaen Corbet $^{\mathrm{d}, \mathrm{e}}$ and Benjamin Miranda Tabak ${ }^{f}$ \\ ${ }^{a}$ Faculty of Business Administration, Bilkent University, Ankara, Turkey; ${ }^{b}$ Universidade Católica De Brasília, Brasília, Brazil; 'Department of \\ Computing and Mathematics, Faculty of Philosophy, Sciences, and Literatures in Ribeirão Preto, University of São Paulo, São Paulo, Brazil; \\ dDCU Business School, Dublin City University, Dublin, Ireland; eSchool of Accounting, Finance and Economics, University of Waikato, Hamilton, \\ New Zealand; 'School of Public Policy and Government at Getulio Vargas Foundation, Brasília-DF, Brazil
}

ABSTRACT

We examine the high-frequency return and volatility of major cryptocurrencies and reveal that spillovers among them exist. Our analysis shows that return and volatility clustering structures are distinct among different cryptocurrencies, suggesting that return and volatility might have different spillover patterns. Further investigation via minimal spanning trees points out that BTC, LTC and ETH are the most relevant cryptocurrencies in general, serving as connection hubs for linking many other cryptocurrencies. However, their role is challenged lately, potentially due to the increased usage of other cryptocurrencies in time.
KEYWORDS

Cryptocurrency; bitcoin; network; spillover; minimal spanning tree; hierarchical clustering; machine learning

\section{Introduction}

The rapid development of cryptocurrencies as a financial product appears to have taken many regulatory systems by surprise. While research to uncover the many systemic repercussions of this digital finance evolution continues to expand at pace, much evidence points towards substantially differing characteristics associated with these new financial products relative to traditional financial products on which much regulation has been honed over time. The development of cryptocurrencies has been further advertised by the unprecedented price appreciations that have taken place across a number of assets, particularly that of Bitcoin. These products have therefore offered substantial opportunities to a number of speculative investors, not to mention a transmission vehicle through which those with illicit needs can take advantage of regulatory circumvention. Research, however, has questioned if this price evolution could be a symptom of other deeper issues, such as the presence of financial bubbles (Corbet, Lucey, and Yarovaya 2018b; Fry 2018). Whether for investment or illicit rationale, demand for cryptocurrency continues to grow and another market issue is the presence of fake cryptocurrency, or frauds as generated within 'pump-and-dump' scenarios (Corbet et al. 2020a).

To identify such illicit tactics, further developing our understanding of cross-product correlations and spillovers is of substantial benefit. For example, Griffins and Shams (2020) investigated Tether's influence in market values of cryptocurrencies. They found that purchases with Tether were timed following market downturns and resulted in substantial rises in Bitcoin prices. Besides, less than $1 \%$ of the hours in which Tether experienced a large volume of transactions is associated with $50 \%$ of the increase in Bitcoin prices and $64 \%$ of other top cryptocurrencies, drawing the damning conclusion that Tether was used to provide price support and manipulate cryptocurrency prices. Along with this source of instability, cryptocurrency exchanges as well as individual currencies have experienced several sophisticated hacking events, further damaging the confidence in this asset class. The resulting sharp declines in the prices of cryptocurrencies are often not just limited to the cryptocurrency that has been targeted, but also spillover to other cryptocurrencies. Also, we

CONTACT Benjamin Miranda Tabak benjaminm.tabak@gmail.com E School of Public Policy and Government at Getulio Vargas Foundation, Brasília-DF, Brazil

*Thiago C. Silva (Grant no. 308171/2019-5, 408546/2018-2) and Benjamin M. Tabak (Grant no. 310541/2018-2, 425123/2018-9) gratefully acknowledge financial support from the CNPq foundation. Ahmet Sensoy gratefully acknowledges support from the Turkish Academy of Sciences - Outstanding Young Scientists Award Programme (TUBA-GEBIP).

2021 Informa UK Limited, trading as Taylor \& Francis Group 
must note that such spillovers can be instigated by a relatively low number of market participants. ${ }^{1}$

Considering such developments and accusations being made with regards to cryptocurrency markets, it is of particular importance that research focuses on mechanisms through which abnormalities and irregular behaviour can be identified. One such point of focus is that of spillovers between cryptocurrency markets, and indeed their changing behaviour over time. In this study, we focus on two type of spillovers among the major cryptocurrencies, namely return and volatility spillovers. Our analysis shows that both types of spillovers exist however they have quite different pattern among cryptocurrencies. We further reveal that BTC, ETH and LTC are the key cryptocurrencies in both of these spillover patterns as they link many cryptocurrencies to each other. On the other hand, we see that their central role among the network has been challenged lately once we focus on only the recent sub-sample of our data. We use a Lasso approach (least absolute shrinkage and selection operator) to estimate the autoregressive vector model (VAR) with all cryptocurrencies. This method allows us to choose only a few coefficients and not all of them in the VAR model, simplifying the model, making it more parsimonious while maintaining good accuracy.

We structure the article as follows. In Section 2, we present a thorough overview of the main cryptocurrency research relating to pricing spillovers that exist to date. In Section 3 we discuss the data used and present some basic statistics. We then briefly present the methodology used to analyse the interconnectivity between the sample cryptocurrencies in Section 4. Section 5 discusses the main empirical results, while we conclude the paper in Section 6.

\section{Previous literature and hypotheses development}

The breadth of coverage relating to research on cryptocurrencies has expanded exponentially in recent years, with a thorough review of such development provided by Corbet et al. (2019b), which outlined price efficiency, price volatility and the presence of criminality within the products and the exchanges on which they trade as of immediate concern. Spillovers within cryptocurrency markets were largely indicative of a number of broad phenomena, while also providing evidence of a maturing and developing financial product. Such developing maturity further has manifested in a number of issues similar to other traditional markets, such as interlinkages between return prediction and liquidity (Wei 2018), varying underlying dynamic process generating the prices and volatility (Bariviera 2017; Celeste, Corbet, and Gurdgiev 2020; Akyildirim et al. 2020b), interactions with monetary policy announcements (Corbet, McHugh, and Meegan 2017; Corbet et al. 2020b), the presence of negative bubbles (Fry and Cheah 2016), heavy tails (Fry 2018; Begusic et al. 2018), mean reversion (Corbet and Katsiampa 2020), finite loss boundaries similar to that of commodity markets with extended left tail correlations (Feng, Wang, and Zhang 2018), long-memory and heteroskedasticity (Phillip, Chan, and Peiris 2018), multifractality (Stavroyiannis et al. 2019; Lahmiri and Bekiros 2020a,b) and indeed, the presence of pricing bubbles (Corbet, Lucey, and Yarovaya 2018b). Yi, Xu, and Wang (2018) identify that connectedness within cryptocurrency markets fluctuates periodically and has presented an increasing trend since 2016. Kumar and Anandarao (2019) found similar results, but particular evidence of volatility spillovers after 2017. Bouri et al. (2018) used ST-VAR GARCH-in-mean models for the period 2010 through 2017 to find that Bitcoin returns move in a similar manner to those of other major asset classes in both bull and bear market states, but such result are time and market dependent should the diversification benefits presented by Corbet et al. (2018c) and Akhtaruzzaman, Sensoy, and Corbet (2020) have continued over time, and indeed Baur, Hong, and Lee (2018) who found contradictory evidence where transaction data supported the product's position as a highly speculative asset. Katsiampa, Corbet, and Lucey (2019a) found differentiating impacts of positive and negative shocks on various cryptocurrencies' conditional volatility, capturing the asymmetric effects of good and bad news accordingly. Further, Katsiampa, Corbet, and Lucey (2019b) used BEKK-GARCH models to

\footnotetext{
${ }^{1}$ See Gandal et al. (2018) which identified the impact of suspicious trading activity on the Mt.Gox Bitcoin exchange theft.
} 
show the existence of bi-directional positive shock transmission effects between Bitcoin and both Ether and Litecoin, and uni-directional shock transmission from Ether to Litecoin. Akyildirim et al. (2020a), while presenting considerable effects of both fraudulent and regulatory unease within the industry on Bitcoin price formation, also verify that Bitcoin derivatives dominate price formation relative to spot markets, while much evidence suggests that these same Bitcoin futures contracts were most likely to be a source of speculation rather than hedging (Corbet et al. 2018a, 2019a). When analysing the cross-correlations between cryptocurrencies, Stosic et al. (2018) found that a major part of the eigenvalues of the cross-correlation matrix do not agree with those of the random matrix theory, suggesting an information-based component hidden in the cross-correlation structure of cryptocurrencies.

While developing a cryptocurrency composite index, Zhang et al. (2018) identified persistent crosscorrelation with the computed index and the Dow Jones Industrial Average. Such cross-correlations are also subjected to the presence of sustained levels of high unconditional volatility with sudden, sharp price swings as outlined by Chaim and Laurini (2018). Similarly, Bouri et al. (2018) found that Bitcoin price movements are quite similar to those of various assets, in particular commodities, thus, Bitcoin is not isolated completely. $\mathrm{Yi}, \mathrm{Xu}$, and Wang (2018) found that 52 cryptocurrencies are strongly interconnected and large-cap cryptocurrencies are the ones that spill volatility over others. OmaneAdjepong and Alagidede (2019) explored market coherency and volatility causal linkages of seven leading cryptocurrencies using wavelet-based methods. The authors find three distinct results including diversification benefits, an ability to somewhat predict volatility feedback linkages and a link between correlations and both trading levels and market volatility. Ji et al. (2019a) found that the linkages between return and volatility was not due to market capitalization when investigating six large cryptocurrencies, specifically finding that Litecoin and Bitcoin are at the core of the connected network of returns, which developed on their other study (Ji et al. 2019b) that used a dynamic entropy-based approach to reveal the direction of return spillovers where cryptocurrency returns are found to become more connected.
This research builds on that which also focused on not just cryptocurrency markets, but traditional financial assets also. When considering commodity markets, Arouri, Jouini, and Nguyen (2012) investigated the volatility spillovers between oil and stock markets in Europe, identifying evidence of significant volatility spillover effects. The identification of such interlinkages are found to be of the utmost importance when considering the role of oil price risk and the process of portfolio management. Ji and Fan (2012) identified strengthening interlinkages during crisis between crude oil and other nonenergy commodity markets. Awartani and Maghyereh (2013) found that return and volatility transmissions are bi-directional, albeit asymmetric between oil and stock markets in the Gulf. Liu et al. (2017) identify varying evolution features of spillover effects between the oil and US stock market, and both oil and Russian stock markets. Das, Bhowmik, and Jana (2018) examined the stock market co-movement and volatility spillover dynamics in the Pacific to find limited diversification benefits, and both strong co-movement and volatility comovements during periods of financial crisis. Baumhl et al. (2018) found that such volatility spillovers decrease when markets are characterized by greater temporal proximity. Such spillovers were also identified between stock returns and exchange rate changes (Kanas, 2000) and throughout European equity markets (Baele 2005), however, such financial market interlinkages were found to have a relatively larger effect on volatility than contagion, but both are statistically significant.

Within the guidance of such research on cryptocurrency, this work focuses on a number of specific hypotheses that provide substantiative information value surround the development of cryptocurrencies as a viable financial product:

$h_{1}$ : Do return spillovers between cryptocurrency markets change over time?

$h_{2}$ : Do volatility spillovers between cryptocurrency markets change over time?

$h_{3}$ : Using hierarchical clustering, are broad cryptocurrency volatility spillovers sourced solely within the largest cryptocurrencies of BTC, ETH and LTC? 


\section{Data}

The high-frequency data used in this study is obtained from Kaiko Digital Asset Store, leading provider of institutional-grade cryptocurrency market data. Kaiko covers raw trade order book data of $10,000+$ currency pairs across $70+$ exchanges. $^{2}$ In this study, we use specifically the data from Bitfinex Exchange as it offers the most liquid order book in the world. Bitfinex platform boasts a suite of order types in addition to margin trading and margin funding, which all make it to be one of the most efficient cryptocurrency exchanges in the world.

The dataset covers the period from 1 April 2013 to 23 June 2018 . The starting date covers only the trade data of Bitcoin. Within this time period, we have 77 cryptocurrencies trading against the US dollar. However, the earliest starting date for many of the cryptocurrency data is 10 August 2017. Hence, to keep the number of cryptocurrencies and number of observations large enough for robust conclusions, we use 15min frequency data with two filtering mechanisms. First, we filter for cryptocurrencies which have data starting on 10 August 2017 (17:45 UTC) and is still available on the last day of our sample, 23 June 2018 (23:45 UTC). Second, we filter for the cryptocurrencies having less than $1 \%$ nontrading time interval within this period. According to these criteria, we have 12 cryptocurrencies, namely Bitcoin Cash $(\mathrm{BCH})$, Bitcoin (BTC), Dash (DSH), EOS (EOS), Ethereum Classic (ETC), Ethereum (ETH), Iota (IOT), Litecoin (LTC), OmiseGO (OMG), Monero (XMR), Ripple (XRP), and Zcash (ZEC). For each coin, we take the 15-min log-returns, i.e. $\ln \left(p_{t+15 m}\right)-\ln \left(p_{t}\right)$, to use in our spillover analysis. For the volatility, squared returns are used. We provide the summary status of cryptocurrency return and squared return series in Tables A1 and A2, respectively. Moreover, the cross-correlation between returns (volatility) series are displayed in Figure A1 (Figure A2).

As of the end of our sample period, there are 1545 different coins traded in the global cryptocurrency markets ${ }^{3}$ where our sample represents more than $79 \%$ of the total market capitalization. Accordingly, sample used in this study is a good representative of the whole cryptocurrency markets.

\section{Methodology}

In Table 1 we present our connectedness table that summarizes the measures we use to compute spillovers ${ }^{4}$ Let $s_{i j}$ be the fraction of cryptocurrency $i$ 's $H$-step forecast error variance due to shocks in cryptocurrency $j$. In this case, the pairwise connectedness from $j$ to $i$ is:

$$
C_{i \leftarrow j}=s_{i j} .
$$

We allow spillovers from cryptocurrencies in each other to be asymmetric $C_{i \leftarrow j} \neq C_{j \leftarrow i}$. Therefore, we can calculate net pairwise connectedness using following expression ${ }^{5}$

$$
C_{i j}=C_{j \leftarrow i}-C_{i \hookleftarrow j} .
$$

The general connectedness measure from all other cryptocurrencies to cryptocurrency $i$ is:

$$
C_{i \leftarrow \bullet}=\sum_{j=1, j \neq i}^{N} s_{i j},
$$

whereas the total directional connectedness from cryptocurrency $j$ to others is:

$$
C_{\bullet \leftarrow j}=\sum_{i=1, i \neq j}^{N} s_{i j} .
$$

\begin{tabular}{|c|c|c|c|c|}
\hline & $r_{1}$ & $r_{2}$ & $r_{N}$ & From others \\
\hline$r_{1}$ & $s_{11}$ & $s_{12}$ & $s_{1 N}$ & $\sum_{j=1}^{N} d_{1 j}, j \neq 1$ \\
\hline$r_{2}$ & $s_{21}$ & $s_{22}$ & $s_{2 N}$ & $\sum_{j=1}^{N} d_{1 j}, j \neq 2$ \\
\hline . & . & . & . & \\
\hline . & . & . & . & \\
\hline$r_{N}$ & $s_{N 1}$ & $s_{N 2}$ & $s_{N N}$ & $\sum_{j=1}^{N} d_{N j}, j \neq N$ \\
\hline To others & $\sum_{i \neq 1}^{N} d_{i 1}$ & $\sum_{i \neq 2}^{N} d_{i 2}$ & $\sum_{i \neq N}^{N} d_{i=1}$ & $\underset{\substack{N \\
i \neq j}}{N} \sum_{i, j=1}^{N} d_{i j}$ \\
\hline
\end{tabular}

Table 1. Structure of the connectedness table.

\footnotetext{
${ }^{2}$ For recent studies that use Kaiko as the data provider, see Makarov and Schoar (2020); Akyildirim et al. (2020a); Aslan and Sensoy (2020); Mensi et al. (2019). ${ }^{3} \mathrm{https}: / /$ coinmarketcap.com/historical/20,180,623/

${ }^{4}$ We follow Diebold and Yilmaz (2012), Diebold and Yilmaz (2014), and Barunik and Krehlik (2018). We use the R packages written by Krehlik (2020), Nicholson, Matteson, and Bien (2019) and Csardi and Nepusz (2006).

${ }^{5}$ We have $\frac{N^{2}-N}{2}$ net pairwise directional connectedness measures.:
} 


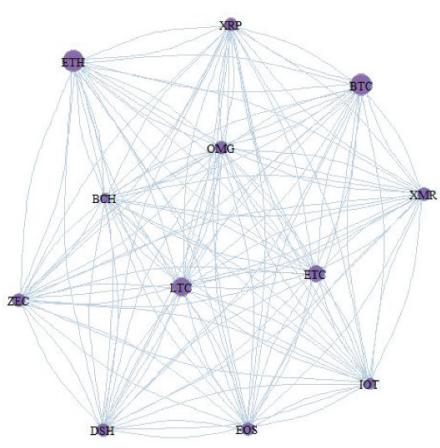

(a) Network - Returns - Full Sample

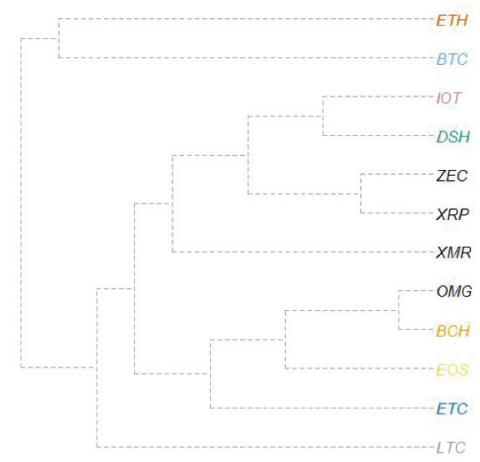

(c) Dendrogram - Returns - Full Sample

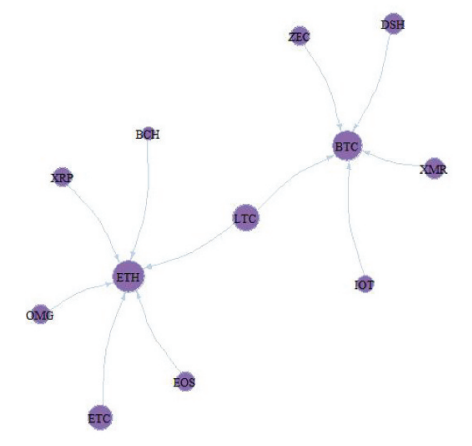

(e) MST - Returns - Full Sample

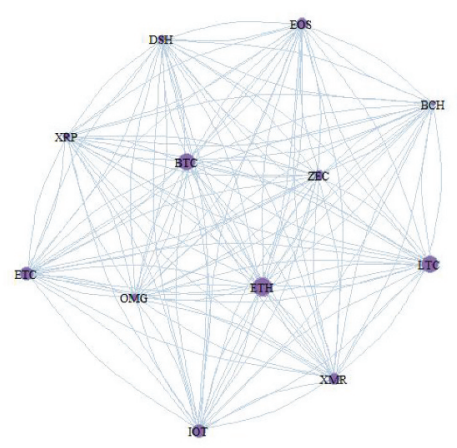

(b) Network - Volatility - Full Sample

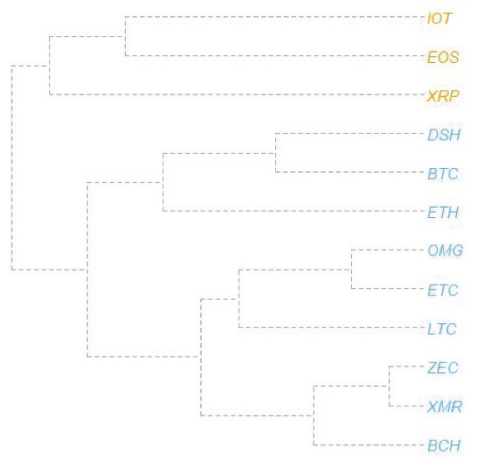

(d) Dendrogram - Volatility - Full Sample

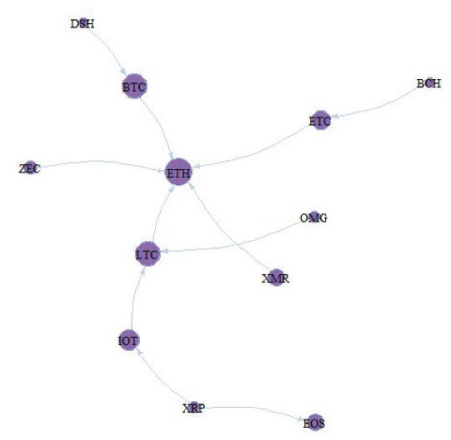

(f) MST - Volatility - Full Sample

Figure 1. Full sample analysis of spillover networks, dendrograms, and minimal spanning trees. Sub-figures on the left panel examine returns whereas sub-figures on the right panel focus on volatilities.

In order to construct our connectedness measures, Optimal lags are chosen according to Bayesian we first estimate a Vector Autoregression (VAR) Information Criterion. Since we are working on including all cryptocurrencies and their lags. return level series which are stationary, no trend 


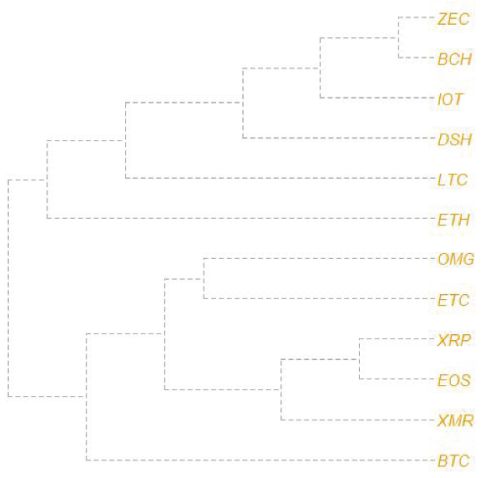

(a) Period 1

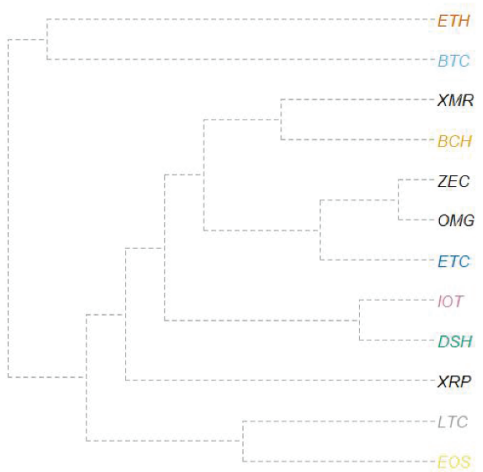

(c) Period 3

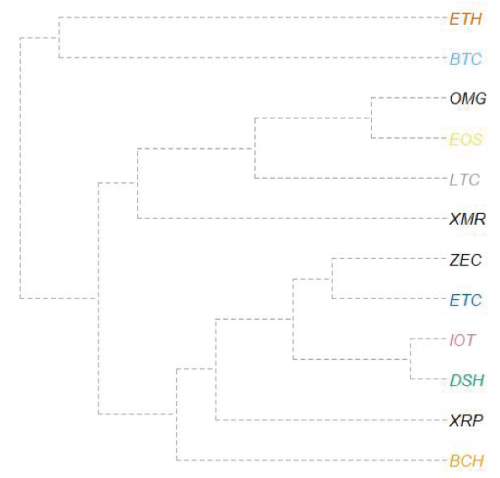

(b) Period 2

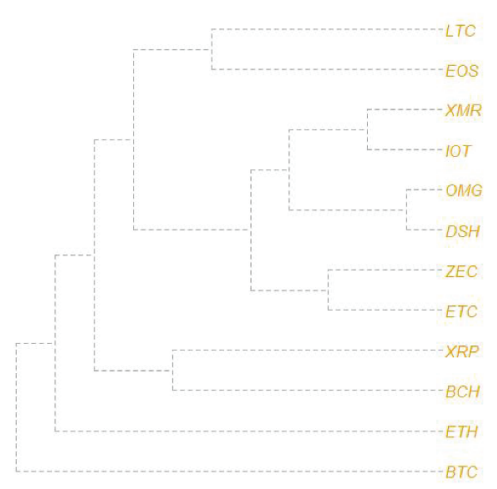

(d) Period 4

Figure 2. Dendrogram - returns spillovers for four non-overlapping sample periods.

variable is included in the VAR model. We use BigVar in $\mathrm{R}$ to employ a Lasso estimator, this procedure effectively shrinks the VAR coefficients that do not contribute to forecasting accuracy to zero. In using this penalty method, we estimate a more parsimonious version of what would otherwise be an overparameterized system. ${ }^{6}$

\section{Empirical results}

The contemporary correlation between cryptocurrencies is relatively high - between 33\% and 73\% and all are statistically significant at the $1 \%$ level. This suggests that cryptocurrencies may be viewed as an asset class. The greater or lesser correlation between these assets should depend on their characteristics, such as use and trading, as well as number of investors, among others. This may suggest that by investing only in cryptocurrencies the investor would be running idiosyncratic risk. This risk could arise, for example, from regulatory changes due to greater difficulties in the use of these assets as a medium of exchange (classical currency function).

In this sense, it would be crucial to evaluate if there is spillover between the different cryptocurrencies. We use a new database - with intraday data - that allows this evaluation in different

${ }^{6}$ We test our procedure for different lag specifications, using 1,3,5 and 10 lags, and results remain qualitatively the same (Kang and Lee (2019)) 


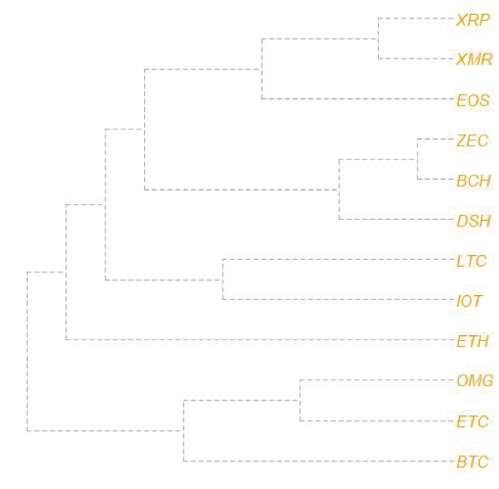

(a) Period 1

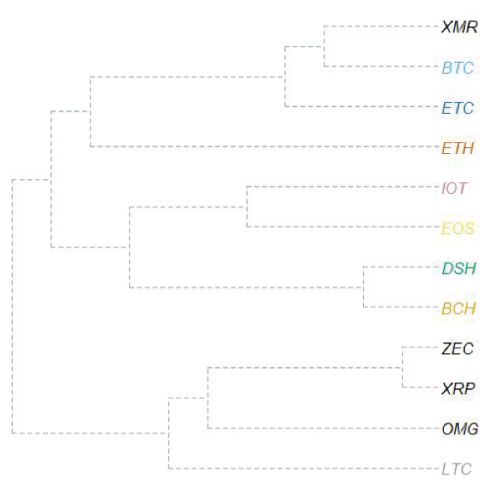

(c) Period 3

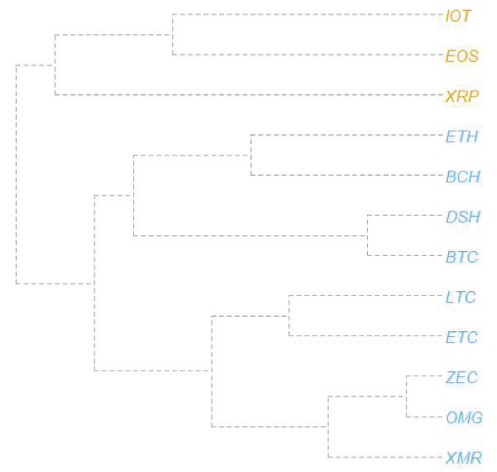

(b) Period 2

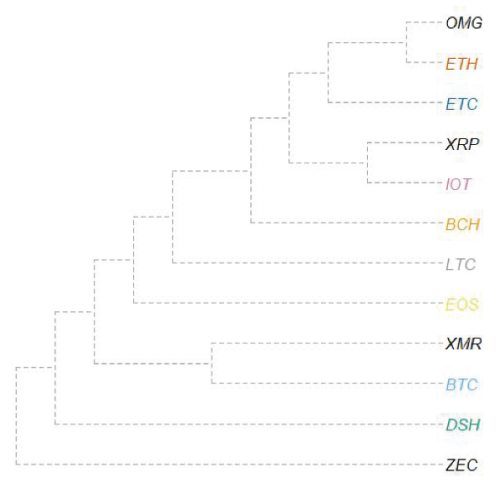

(d) Period 4

Figure 3. Dendrogram - volatility spillovers for four non-overlapping sample periods.

periods of time. Cryptocurrencies are a relatively new type of asset and as a result, a number of inefficiencies may arise, reflecting on their prices and their evolution over time. Spillovers may reflect these inefficiencies as well as being from a particular asset class.

Figure 1 presents the network, dendrogram and Minimum Spanning Tree for all cryptocurrencies in our sample and the entire sample. In the upper part of the figure, we show that all cryptocurrencies are interconnected for both returns and volatility. The size of the node represents how relevant is that particular cryptocurrency in generating spillover to others cryptocurrencies. Our results suggest some degree of heterogeneity in the relative impact of specific cryptocurrencies.
We also present the Dendrogram - Hierarchical clustering for all cryptocurrencies in our sample. When we focus on the returns we find that ETH and BTC appear separate in a cluster, whereas all others are in a different cluster. LTC appears by itself in the second cluster. An interesting finding is that the structure of clustering is quite different for volatility. This suggests that volatility spillovers may present a significantly different pattern from return spillovers. Therefore, risk managers and practitioners should evaluate both when deciding investment and taking portfolio reallocation decisions.

The Minimum Spanning Tree complements this information. When we evaluate results for returns we see that there are two main cryptocurrencies BTC and ETH, which are linked to all others. These 
two are connected through LTC. Results for volatility are quite different, with ETH being one of the main cryptocurrencies in the sample - linking most of the cryptocurrencies. This result is relevant for investors or risk managers that have to decide how to allocate investments across cryptocurrencies or how to limit risks in the portfolio. BTC, ETH and LTC seem to be relevant cryptocurrencies to keep track as they may link spillovers from a subset of cryptocurrencies to others.

For further analysis, we divide the sample into four equal non-overlapping intervals and perform a sub-period analysis to observe whether we see drastic changes through time with regard to return and volatility spillover relationship between sample cryptocurrencies. Figure 2 presents the dendrogram for these four distinct and nonoverlapping time periods. Although ETH, BTC and LTC still seem to be key-players in the cryptocurrency market their role - in terms of return spillover seems to be changing overtime. This may be due to several factors such as changes in the uses and investment decisions on these cryptocurrencies, but also due to regulatory changes that are occurring worldwide.

Figure 3 on the other hand, displays a large change in the hierarchical clustering. Volatility clustering seem to change more abruptly than returns for the cryptocurrencies in our sample. Therefore, risk spillovers may change even more significantly overtime than return, which suggests that keeping track of volatility spillovers seems to

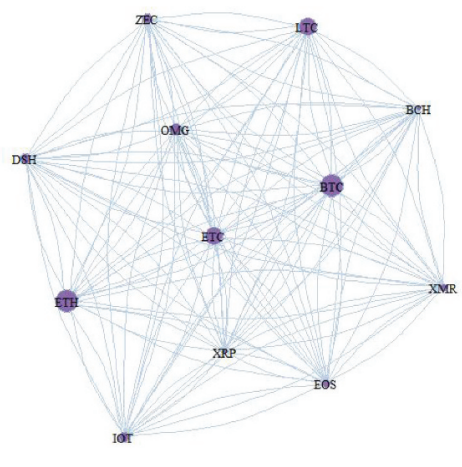

(a) Period 1

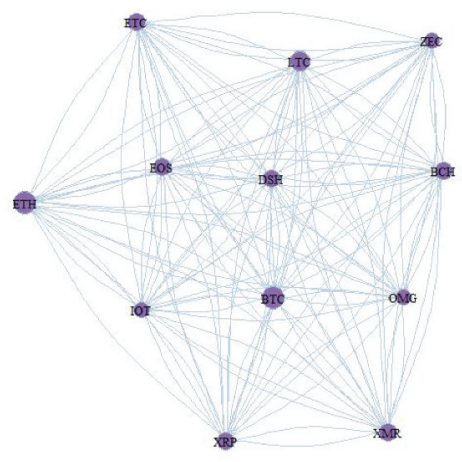

(c) Period 3

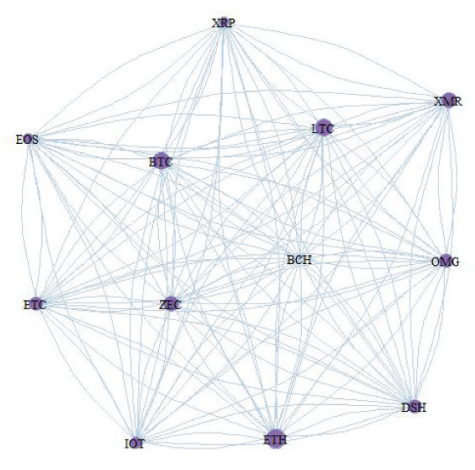

(b) Period 2

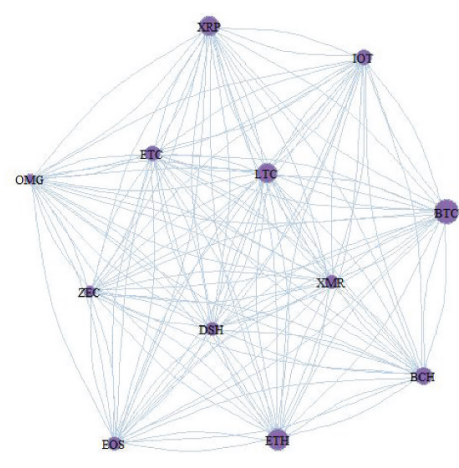

(d) Period 4

Figure 4. Network analysis - cryptocurrency return spillovers for four non-overlapping sample periods. 


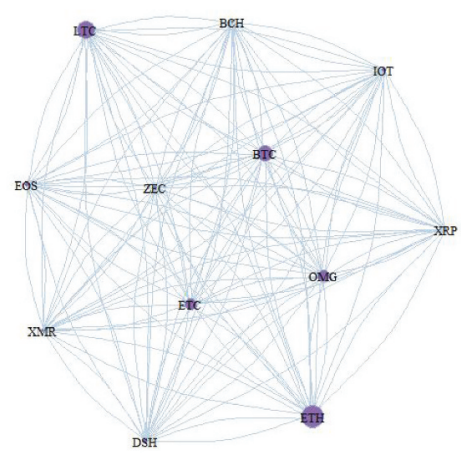

(a) Period 1

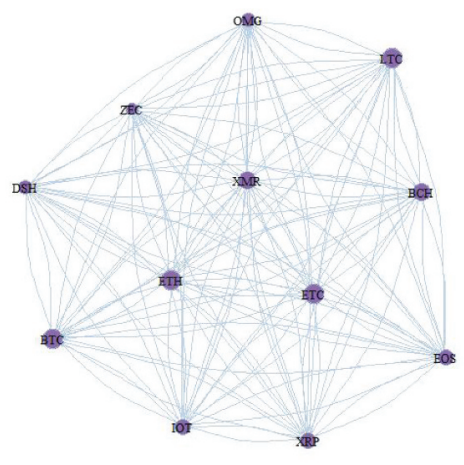

(c) Period 3

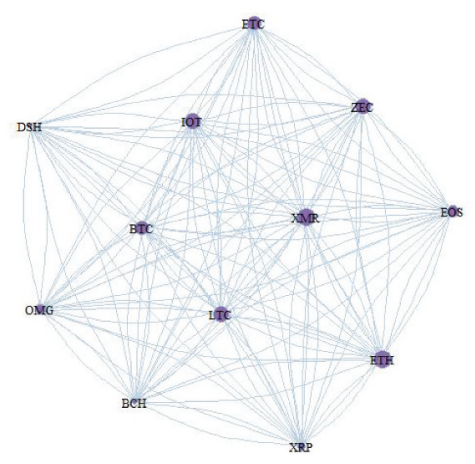

(b) Period 2

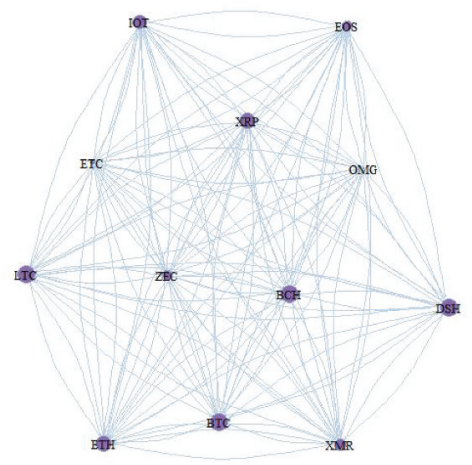

(d) Period 4

Figure 5. Network analysis - cryptocurrency volatility spillovers for four non-overlapping sample periods.

be specially relevant in this market. The changing nature of the clusters suggests that rebalancing portfolios that are specialized in these assets should be done on a more frequent basis than we would do on more mature markets such as equity or bonds. Quarterly re-balancing may be better than yearly as the dynamics of these assets' connectedness may change substantially over time.

We also evaluate the total connectedness in a return network (Figure 4) and volatility network (Figure 5) and find that these cryptocurrencies are strongly linked overtime. Although the nature and the relevance of specific assets may change over time they hold as an asset class. The changing size of specific nodes may reflect, similarly to what we find using the dendrogram, how the relative importance of these assets change over time.

When we evaluate changes in the Minimum Spanning Tree over our sub-periods we find that the role of BTC, LTC and ETH remains important throughout the entire period (Figure 6). These cryptocurrencies are in the centre of the MST, linked to many others, in every sub-period. However, the evaluation of risk spillovers reveal that the relative importance of specific cryptocurrencies may be changing overtime (Figure 7). Other cryptocurrencies appear relevant as we use more recent data - XMR, ETC, BCH and DSH. Therefore, as cryptocurrencies are created risk managers would benefit from calculating risk 


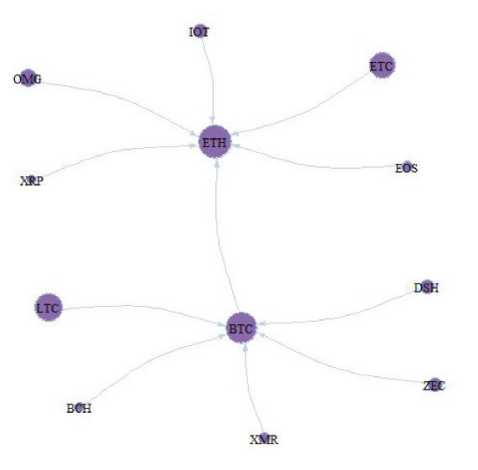

(a) Period 1

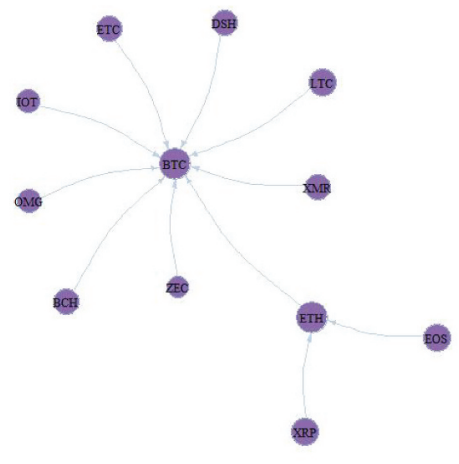

(c) Period 3

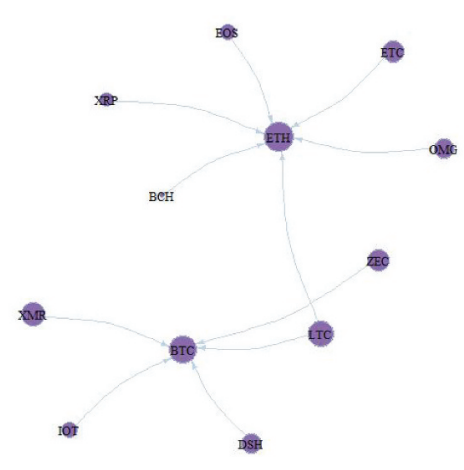

(b) Period 2

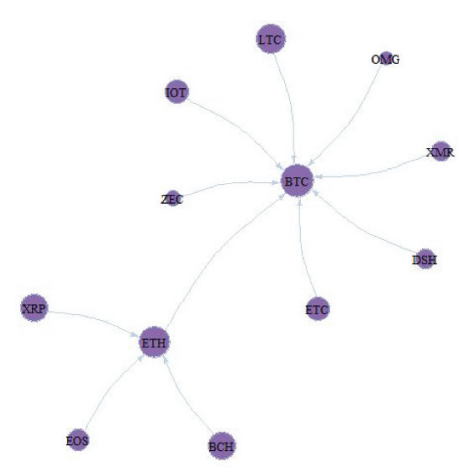

(d) Period 4

Figure 6. MST analysis - cryptocurrency returns spillovers for four non-overlapping sample periods.

spillovers between them and tracking down the evolution of these spillovers.

\section{V.I. Robustness tests}

In Table A3 we present the spillover of the network into each of the cryptocurrencies. This measure is directly taken from the forecast error variance decomposition. The first value in column al corresponds to how much of the forecast error variance for ETH stems from shocks received from other cryptocurrencies, for the subsample al. This value is $100 \%$ minus the autoregressive term's contribution to forecast error variance. The last row denotes the network's total connectivity, taken as a sum of the column in decimal values. As we can the return spillover changes over time (for the different subsamples).

Table A4 shows the total contribution of each asset to the total network connectivity, as a percentage term. ${ }^{7}$ As we can see from the results, the ranking changes slightly over time (depending on the subsample), suggesting that these cryptocurrencies' relative importance varies.

We also present the Tables for the volatility connectivity which derives similar results (Table A5 and Table A6). The relative importance of these cryptocurrencies change slightly over time.

In Table A7 we present the results of the $\operatorname{GARCH}(1,1)$ estimation for each cryptocurrency.

${ }^{7}$ This is calculated as the total spillover from each asset divided by the total connectivity measure 


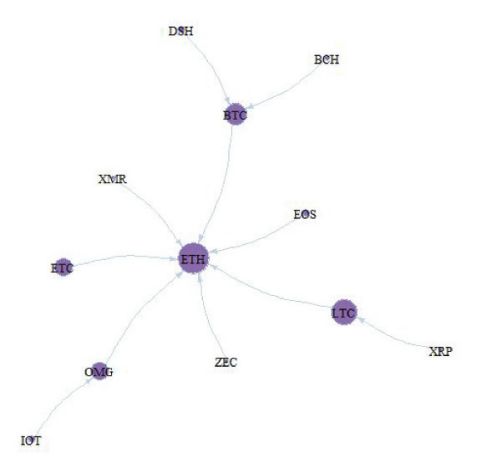

(a) Period 1

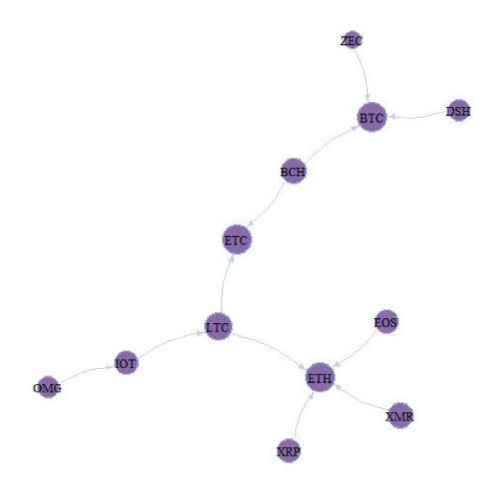

(c) Period 3

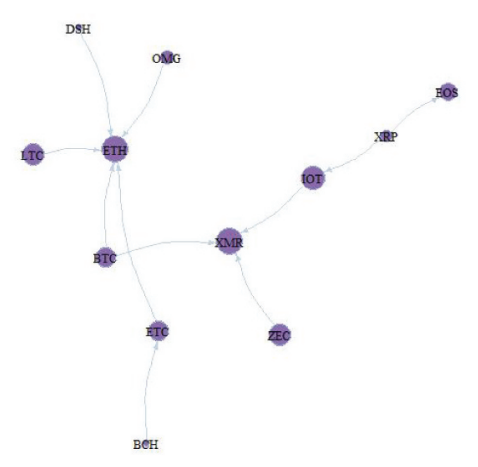

(b) Period 2

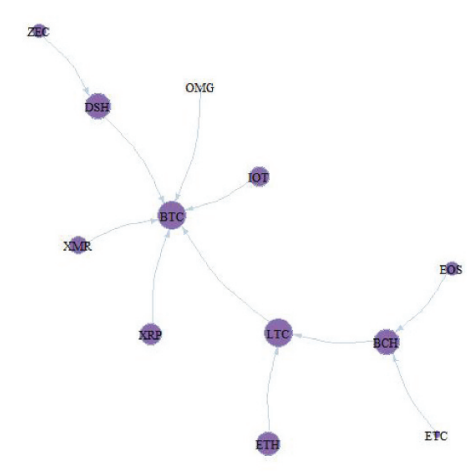

(d) Period 4

Figure 7. MST analysis - cryptocurrency volatility spillovers for four non-overlapping sample periods.

We use the residuals filtered for a $\operatorname{GARCH}(1,1)$ model to estimate the LASSO-VAR using our baseline specification, with three lags $(p=3)$. In Table A8 we present results for the baseline case, the GARCH-filtered returns, using ten lags $(p=10)$ and the GARCH-filtered returns using 10 lags. As we can see, the results remain qualitatively similar, with very little change.

We also perform this exercise for the percentage of connectivity from and results remain very similar (Table A9). We find that changes occur when we split the sample. Therefore, the relative importance of these cryptocurrencies may change over time. However, the lag length or filtering for GARCH effects has minimal impact on the results, suggesting the results are robust for these changes.

\section{Final considerations}

Using intraday data of the most popular 12 cryptocurrencies (that cover $80 \%$ of the total cryptocurrency market capitalization), we find that there are relevant return and volatility spillovers between them. However, when we analyse hierarchical clustering for our sample cryptocurrencies, return and volatility clustering structures are quite different than each other suggesting that return and volatility might have different spillover patterns. Examining the minimal spanning tree structures reveals that BTC, LTC and ETH are the most relevant cryptocurrencies as they link many others cryptocurrencies between themselves. However, their role is challenged in time (especially in the case of 
volatility spillovers) as we split our sample into non-overlapping periods and focus on more recent data.

These changes in the dynamics of return and volatility spillovers may reflect many changes that have been occurring in this market such as regulatory changes that have been introduced worldwide to cope with the innovations in financial markets and the increased usage of cryptocurrencies as medium of exchange (money function) and investment opportunity.

From a policy-making perspective, such results are quite important. While Bitcoin remains the largest and most well-known cryptocurrency, results suggest that it does not continue to generate most of the centralized volatility within broad cryptocurrency markets. In fact, evidence suggests that the three largest cryptocurrencies, who would have possessed core influence upon other, more illiquid and smaller cryptocurrencies, no longer have such control. Such evidence indicates further evolution of international cryptocurrency markets, containing a number of self-sufficient, volatility generating and detached products that are obtaining more independence from the original market dominating currencies, indicating a dilution of influence from market regulation plans from within the largest and most liquid products alone.

\section{Disclosure statement}

No potential conflict of interest was reported by the authors.

\section{Funding}

This work was supported by the Conselho Nacional de Desenvolvimento Científico e Tecnológico [425123/20189,308171/2019-5,310541/2018-2,408546/2018-2]; Türkiye Bilimler Akademisi.

\section{ORCID}

Thiago Christiano Silva (D) http://orcid.org/0000-0003-26314393

\section{References}

Akhtaruzzaman, M., A. Sensoy, and S. Corbet. 2020. “The Influence of Bitcoin on Portfolio Diversification and Design." Finance Research Letters 37: 101344. doi:10.1016/ j.frl.2019.101344.

Akyildirim, E., S. Corbet, P. Katsiampa, N. Kellard, and A. Sensoy. 2020a. "The Development of Bitcoin Futures: Exploring the Interactions between Cryptocurrency Derivatives." Finance Research Letters 37: 101234. doi:10.1016/j.frl.2019.07.007.

Akyildirim, E., S. Corbet, B. Lucey, A. Sensoy, and L. Yarovaya. 2020b. "The Relationship between Implied Volatility and Cryptocurrency Returns.” Finance Research Letters 33: 101212. doi:10.1016/j.frl.2019.06.010.

Arouri, M., J. Jouini, and D. Nguyen. 2012. "On the Impacts of Oil Price Fluctuations on European Equity Markets: Volatility Spillover and Hedging Effectiveness." Energy Economics 34 (2): 611-617. doi:10.1016/j. eneco.2011.08.009.

Aslan, A., and A. Sensoy. 2020. "Intraday Efficiency-frequency Nexus in the Cryptocurrency Markets." Finance Research Letters 35: 101298. doi:10.1016/j.frl.2019.09.013.

Awartani, B., and A. Maghyereh. 2013. "Dynamic Spillovers between Oil and Stock Markets in the Gulf Cooperation Council Countries." Energy Economics 36: 28-42. doi:10.1016/j.eneco.2012.11.024.

Baele, L. 2005. "Volatility Spillover Effects in European Equity Markets." Journal of Financial and Quantitative Analysis 40 (2): 373-401. doi:10.1017/S0022109000002350.

Bariviera, A. 2017. "The Inefficiency of Bitcoin Revisited: A Dynamic Approach.” Economics Letters 161: 1-4. doi:10.1016/j.econlet.2017.09.013.

Barunik, J., and T. Krehlik. 2018. "Measuring the Frequency Dynamics of Financial Connectedness and Systemic Risk ${ }^{\star}$." Journal of Financial Econometrics 16 (2): 271-296. doi:10.1093/jjfinec/nby001.

Baumhl, E., E. Koenda, A. Lycsa, and T. Vrost. 2018. "Networks of Volatility Spillovers among Stock Markets." Physica A: Statistical Mechanics and Its Applications 490: 1555-1574. doi:10.1016/j.physa.2017.08.123.

Baur, D., K. Hong, and A. Lee. 2018. "Bitcoin: Medium of Exchange or Speculative Assets?” Journal of International Financial Markets, Institutions and Money 54: 177-189. doi:10.1016/j.intfin.2017.12.004.

Begusic, S., Z. Kostanjar, H. Eugene Stanley, and B. Podobnik. 2018. "Scaling Properties of Extreme Price Fluctuations in Bitcoin Markets." Physica A: Statistical Mechanics and Its Applications 510: 400-406. doi:10.1016/j.physa.2018.06.131.

Bouri, E., M. Das, R. Gupta, and D. Roubaud. 2018. "Spillovers between Bitcoin and Other Assets during Bear and Bull Markets." Applied Economics 50 (55): 5935-5949. doi:10.1080/00036846.2018.1488075.

Celeste, V., S. Corbet, and C. Gurdgiev. 2020. "Fractal Dynamics and Wavelet Analysis: Deep Volatility and Return Properties of Bitcoin, Ethereum and Ripple." 
Quarterly Review of Economics and Finance 76: 310-324. doi:10.1016/j.qref.2019.09.011.

Chaim, P., and M. Laurini. 2018. "Volatility and Return Jumps in Bitcoin." Economics Letters 173: 158-163. doi:10.1016/j. econlet.2018.10.011.

Corbet, S., D. Cumming, B. Lucey, M. Peat, and S. Vigne. 2020a. "The Destabilising Effects of Cryptocurrency Cybercriminality." Economics Letters 191: 108741. doi:10.1016/j.econlet.2019.108741.

Corbet, S., and P. Katsiampa. 2020. "Asymmetric Mean Reversion of Bitcoin Price Returns." International Review of Financial Analysis 71: 101267. doi:10.1016/j. irfa.2018.10.004.

Corbet, S., C. Larkin, B. Lucey, A. Meegan, and L. Yarovaya. 2020b. "Cryptocurrency Reaction to Fomc Announcements: Evidence of Heterogeneity Based on Blockchain Stack Position." Journal of Financial Stability 46: 100706. doi:10.1016/j.jfs.2019.100706.

Corbet, S., B. Lucey, M. Peat, and S. Vigne. 2018a. "Bitcoin Futureswhat Use are They?” Economics Letters 172: 23-27. doi:10.1016/j.econlet.2018.07.031.

Corbet, S., B. Lucey, M. Peat, and S. Vigne. 2019a. "What Sort of Asset? Bitcoin Analysed." Lecture Notes in Business Information Processing 345: 52-65.

Corbet, S., B. Lucey, A. Urquhart, and L. Yarovaya. 2019b. "Cryptocurrencies as A Financial Asset: A Systematic Analysis.” Inter- National Review of Financial Analysis 62: 182-199. doi:10.1016/j.irfa.2018.09.003.

Corbet, S., B. Lucey, and L. Yarovaya. 2018b. "Datestamping the Bitcoin and Ethereum Bubbles." Finance Research Letters 26: 81-88. doi:10.1016/j.frl.2017.12.006.

Corbet, S., G. McHugh, and A. Meegan. 2017. “The Influence of Central Bank Monetary Policy Announcements on Cryptocurrency Return Volatility." Investment Management and Financial Innovations 14 (4): 60-72. doi:10.21511/imfi.14(4).2017.07.

Corbet, S., A. Meegan, C. Larkin, B. Lucey, and L. Yarovaya. 2018c. "Exploring the Dynamic Relationships between Cryptocur- Rencies and Other Financial Assets." Economics Letters 165: 28-34. doi:10.1016/j.econlet.2018.01.004.

Csardi, G., and T. Nepusz. 2006. "The Igraph Software Package for Complex Network Research." InterJournal, Complex Systems 1695 URL: http://igraph.org

Das, D., P. Bhowmik, and R. Jana. 2018. "A Multiscale Analysis of Stock Return Co-movements and Spillovers: Evidence from Pacific Developed Markets." Physica A: Statistical Mechanics and Its Applications 502: 379-393. doi:10.1016/j.physa.2018.02.143.

Diebold, F. X., and K. Yilmaz. 2012. "Better to Give than to Receive: Predictive Directional Measurement of Volatility Spillovers." International Journal of Forecasting 28 (1): 57-66. Special Section 1: The Predictability of Financial Markets Special Section 2: Credit Risk Modelling and Forecasting. doi:10.1016/j.ijforecast.2011.02.006.

Diebold, F. X., and K. Yilmaz. 2014. "On the Network Topology of Variance Decompositions: Measuring the Connectedness of Financial Firms." Journal of
Econometrics 182 (1): 119-134. Causality, Prediction, and Specification Analysis: Recent Advances and Future Directions. doi:10.1016/j.jeconom.2014.04.012.

Feng, W., Y. Wang, and Z. Zhang. 2018. "Can Cryptocurrencies Be a Safe Haven: A Tail Risk Perspective Analysis." Applied Economics 50 (44): 4745-4762. doi:10.1080/00036846.2018.1466993.

Fry, J. 2018. "Booms, Busts and Heavy-tails: The Story of Bitcoin and Cryptocurrency Markets?" Economics Letters 171: 225-229. doi:10.1016/j.econlet.2018.08.008.

Fry, J., and E.-T. Cheah. 2016. "Negative Bubbles and Shocks in Cryptocurrency Markets." International Review of Financial Analysis 47: 343-352. doi:10.1016/j. irfa.2016.02.008.

Gandal, N., J. Hamrick, T. Moore, and T. Oberman. 2018. "Price Manipulation in the Bitcoin Ecosystem." Journal of Monetary Economics 95: 86-96. doi:10.1016/j. jmoneco.2017.12.004.

Griffins, J., and A. Shams. 2020. "Is Bitcoin Really Un-tethered?" Journal of Finance 75 (4): 1913-1964. doi:10.1111/jofi.12903.

Ji, Q., E. Bouri, C. Lau, and D. Roubaud. 2019a. "Dynamic Connectedness and Integration in Cryptocurrency Markets." International Review of Financial Analysis 63: 257-272. doi:10.1016/j.irfa.2018.12.002.

Ji, Q., E. Bouri, D. Roubaud, and L. Kristoufek. 2019 b. "Information Interdependence among Energy, Cryptocurrency and Major Commodity Markets." Energy Economics 81: 1042-1055. doi:10.1016/j.eneco.2019.06.005.

Ji, Q., and Y. Fan. 2012. "How Does Oil Price Volatility Affect Non-energy Commodity Markets? Applied Energy, 89, 273-280. Kanas, A. (2000). Volatility Spillovers between Stock Returns and Exchange Rate Changes: International Evidence." Journal of Business Finance and Accounting 27: 447-467.

Kang, S. H., and J. W. Lee. 2019. "The Network Connectedness of Volatility Spillovers across Global Futures Markets.” Physica A: Statistical Mechanics and Its Applications 526: 120756. doi:10.1016/j.physa.2019.03.121.

Katsiampa, P., S. Corbet, and B. Lucey. 2019a. "High Frequency Volatility Co-movements in Cryptocurrency Markets." Journal of International Financial Markets, Institutions and Money 62: 35-52. doi:10.1016/j. intfin.2019.05.003.

Katsiampa, P., S. Corbet, and B. Lucey. 2019b. "Volatility Spillover Effects in Leading Cryptocurrencies: A Bekk-mgarch Analysis." Finance Research Letters 29: 68-74. doi:10.1016/j.frl.2019.03.009.

Krehlik, T. (2020). "Frequency Connectedness: Spectral Decomposition of Connectedness Measures." URL: https:/CRAN.R-project.org/package=frequencyConnected nessrpackageversion 0.2.2

Kumar, A., and S. Anandarao. 2019. "Volatility Spillover in Crypto-currency Markets: Some Evidences from Garch and Wavelet Analysis.” Physica A: Statistical Mechanics and Its Applications 524: 448-458. doi:10.1016/j. physa.2019.04.154. 
Lahmiri, S., and S. Bekiros. 2020a. "Big Data Analytics Using Multi-fractal Wavelet Leaders in High-frequency Bitcoin Markets." Chaos, Solitons Fractals 131: 109472. doi:10.1016/j.chaos.2019.109472.

Liu, X., H. An, S. Huang, and S. Wen. 2017. “The Evolution of Spillover Effects between Oil and Stock Markets across Multi-scales Using a Wavelet-based Garchbekk Model.” Physica A: Statistical Mechanics and Its Applications 465: 374-383. doi:10.1016/j.physa.2016.08.043.

Makarov, I., and A. Schoar. 2020. "Trading and Arbitrage in Cryptocurrency Markets.” Journal of Financial Economics 135 (2): 293-319. doi:10.1016/j.jfineco.2019.07.001.

Mensi, W., Y.-J. Lee, K. H. Al-Yahyaee, A. Sensoy, and S.M. Yoon. 2019. "Intraday Downward/upward Multifractality and Long Memory in Bitcoin and Ethereum Markets: An Asymmetric Multifractal Detrended Fluctuation Analysis." Finance Research Letters 31: 19-25. doi:10.1016/j.frl.2019.03.029.

Nicholson, W., D. Matteson, and J. Bien (2019). "BigVAR: Dimension Reduction Methods for Multivariate Time Series." URL: https://CRAN.R-project.org/package= BigVARrpackageversion1.0.6

Omane-Adjepong, M., and I. Alagidede. 2019. "Multiresolution Analysis and Spillovers of Major Cryptocurrency Markets."
Research in International Business and Finance 49: 191-206. doi:10.1016/j.ribaf.2019.03.003.

Phillip, A., J. Chan, and S. Peiris. 2018. "A New Look at Cryptocurrencies.” Economics Letters 163: 6-9. doi:10.1016/j.econlet.2017.11.020.

Stavroyiannis, S., V. Babalos, S. Bekiros, S. Lahmiri, and G. S. Uddin. 2019. "The High Frequency Multifractal Properties of Bitcoin.” Physica A: Statistical Mechanics and Its Applications 520: 62-71. doi:10.1016/j.physa.2018.12.037.

Stosic, D., D. Stosic, T. Ludermir, and T. Stosic. 2018. "Collective Behavior of Cryptocurrency Price Changes." Physica A: Statistical Mechanics and Its Applications 507: 499-509. doi:10.1016/j.physa.2018.05.050.

Wei, W. 2018. "Liquidity and Market Efficiency in Cryptocurrencies." Economics Letters 168: 21-24. doi:10.1016/j.econlet.2018.04.003.

Yi, S., Z. Xu, and G.-J. Wang. 2018. "Volatility Connectedness in the Cryptocurrency Market: Is Bitcoin a Dominant Cryptocurrency?" International Review of Financial Analysis 60: 98-114. doi:10.1016/j.irfa.2018.08.012.

Zhang, W., P. Wang, X. Li, and D. Shen. 2018. “The Inefficiency of Cryptocurrency and Its Cross-correlation with Dow Jones Industrial Average." Physica A: Statistical Mechanics and Its Applications 510: 658-670. doi:10.1016/j.physa.2018.07.032. 


\section{Appendix}

Table A1. Summary statistics for cryptocurrencies' returns.

\begin{tabular}{|c|c|c|c|c|c|c|c|}
\hline Statistic & $\mathrm{N}$ & Mean & St. Dev. & Min & Pctl(25) & $\operatorname{Pctl}(75)$ & Max \\
\hline $\mathrm{BCH}$ & 30,456 & 0.00003 & 0.011 & -0.179 & -0.004 & 0.004 & 0.192 \\
\hline BTC & 30,456 & 0.00002 & 0.007 & -0.082 & -0.003 & 0.003 & 0.055 \\
\hline DSH & 30,456 & 0.00001 & 0.008 & -0.086 & -0.003 & 0.003 & 0.188 \\
\hline EOS & 30,456 & 0.00005 & 0.011 & -0.194 & -0.005 & 0.005 & 0.174 \\
\hline ETC & 30,456 & -0.00000 & 0.009 & -0.154 & -0.004 & 0.003 & 0.127 \\
\hline ETH & 30,456 & 0.00001 & 0.007 & -0.083 & -0.003 & 0.003 & 0.106 \\
\hline IOT & 30,456 & 0.00002 & 0.012 & -0.259 & -0.005 & 0.005 & 0.213 \\
\hline LTC & 30,456 & 0.00002 & 0.009 & -0.125 & -0.003 & 0.003 & 0.120 \\
\hline OMG & 30,456 & 0.00001 & 0.011 & -0.143 & -0.005 & 0.004 & 0.191 \\
\hline XMR & 30,456 & 0.00003 & 0.009 & -0.113 & -0.004 & 0.004 & 0.139 \\
\hline XRP & 30,456 & 0.00003 & 0.011 & -0.315 & -0.004 & 0.004 & 0.315 \\
\hline ZEC & 30,456 & -0.00001 & 0.009 & -0.131 & -0.004 & 0.003 & 0.146 \\
\hline
\end{tabular}

Table A2. Summary statistics for cryptocurrencies' squared-returns.

\begin{tabular}{|c|c|c|c|c|c|c|c|}
\hline Statistic & $\mathrm{N}$ & Mean & St. Dev. & Min & $\operatorname{Pctl}(25)$ & $\operatorname{Pctl}(75)$ & Max \\
\hline $\mathrm{BCH}$ & 30,456 & 0.0001 & 0.001 & 0.000 & 0.00000 & 0.0001 & 0.037 \\
\hline BTC & 30,456 & 0.00004 & 0.0001 & 0.000 & 0.00000 & 0.00003 & 0.007 \\
\hline DSH & 30,456 & 0.0001 & 0.0003 & 0.000 & 0.00000 & 0.00004 & 0.035 \\
\hline EOS & 30,456 & 0.0001 & 0.001 & 0.000 & 0.00000 & 0.0001 & 0.038 \\
\hline ETC & 30,456 & 0.0001 & 0.0004 & 0.000 & 0.00000 & 0.0001 & 0.024 \\
\hline ETH & 30,456 & 0.0001 & 0.0002 & 0.000 & 0.00000 & 0.00003 & 0.011 \\
\hline IOT & 30,456 & 0.0002 & 0.001 & 0.000 & 0.00000 & 0.0001 & 0.067 \\
\hline LTC & 30,456 & 0.0001 & 0.0003 & 0.000 & 0.00000 & 0.00004 & 0.016 \\
\hline OMG & 30,456 & 0.0001 & 0.0005 & 0.000 & 0.00000 & 0.0001 & 0.037 \\
\hline XMR & 30,456 & 0.0001 & 0.0003 & 0.000 & 0.00000 & 0.0001 & 0.019 \\
\hline XRP & 30,456 & 0.0001 & 0.001 & 0.000 & 0.00000 & 0.0001 & 0.099 \\
\hline ZEC & 30,456 & 0.0001 & 0.0003 & 0.000 & 0.00000 & 0.0001 & 0.021 \\
\hline
\end{tabular}

\begin{tabular}{|c|c|c|c|c|c|c|c|c|c|c|c|}
\hline $\mathrm{BCH}$ & & & & & & & 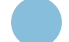 & & & & \\
\hline 0.43 & BTC & & & & & & & & & & \\
\hline 0.36 & 0.59 & $\mathrm{DSH}$ & & & & & & & & & \\
\hline 0.36 & 0.56 & 0.42 & EOS & & & & & & & & \\
\hline 0.42 & 0.62 & 0.52 & 0.5 & ETC & & & & & & & \\
\hline 0.48 & 0.73 & 0.57 & 0.59 & 0.66 & ETH & & & & & & \\
\hline 0.33 & 0.55 & 0.41 & 0.43 & 0.47 & 0.55 & IOT & & & & & \\
\hline 0.43 & 0.71 & 0.53 & 0.51 & 0.6 & 0.7 & 0.51 & LTC & & & & \\
\hline 0.33 & 0.54 & 0.44 & 0.42 & 0.49 & 0.57 & 0.42 & 0.52 & OMG & & & \\
\hline 0.35 & 0.61 & 0.52 & 0.43 & 0.51 & 0.57 & 0.43 & 0.54 & 0.44 & XMR & & \\
\hline 0.34 & 0.53 & 0.43 & 0.45 & 0.48 & 0.55 & 0.42 & 0.5 & 0.41 & 0.44 & XRP & \\
\hline 0.35 & 0.57 & 0.49 & 0.43 & 0.5 & 0.56 & 0.41 & 0.52 & 0.44 & 0.5 & 0.42 & ZEC \\
\hline
\end{tabular}

Figure A1. Plot of the contemporaneous correlation of returns of cryptocurrencies. 


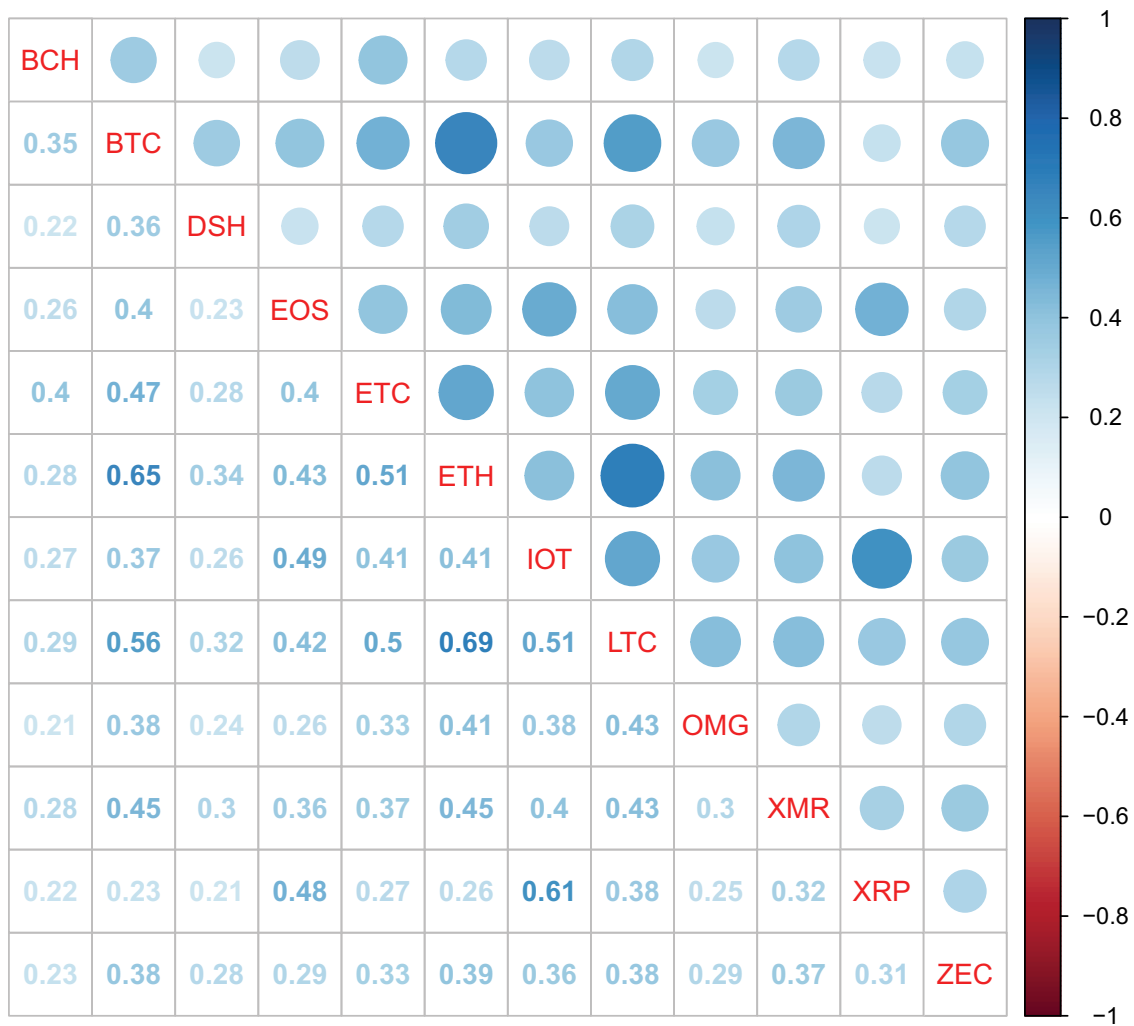

Figure A2. Plot of the contemporaneous correlation of volatility of cryptocurrencies.

Table A3. Return spillovers between cryptocurrencies.

\begin{tabular}{|c|c|c|c|c|c|}
\hline To & a1 & a2 & a3 & a4 & Full Sample \\
\hline ETH & $73.19 \%$ & $73.40 \%$ & $87.31 \%$ & $82.95 \%$ & $79.74 \%$ \\
\hline BTC & $72.05 \%$ & $72.65 \%$ & $87.74 \%$ & $83.64 \%$ & $79.44 \%$ \\
\hline LTC & $69.63 \%$ & $70.80 \%$ & $86.29 \%$ & $81.69 \%$ & $77.45 \%$ \\
\hline ETC & $68.28 \%$ & $67.09 \%$ & $85.73 \%$ & $79.18 \%$ & $75.63 \%$ \\
\hline OMG & $59.18 \%$ & $65.15 \%$ & $84.09 \%$ & $69.40 \%$ & $70.39 \%$ \\
\hline DSH & $56.44 \%$ & $65.62 \%$ & $85.10 \%$ & $75.67 \%$ & $72.86 \%$ \\
\hline ZEC & $53.73 \%$ & $68.70 \%$ & $83.75 \%$ & $71.86 \%$ & $71.87 \%$ \\
\hline IOT & $53.35 \%$ & $60.64 \%$ & $84.16 \%$ & $78.68 \%$ & $69.54 \%$ \\
\hline EOS & $52.80 \%$ & $59.97 \%$ & $86.01 \%$ & $76.67 \%$ & $70.66 \%$ \\
\hline XMR & $51.73 \%$ & $69.69 \%$ & $85.05 \%$ & $75.43 \%$ & $73.11 \%$ \\
\hline $\mathrm{BCH}$ & $44.44 \%$ & $35.29 \%$ & $85.68 \%$ & $80.87 \%$ & $61.81 \%$ \\
\hline XRP & $43.08 \%$ & $56.78 \%$ & $85.99 \%$ & $81.32 \%$ & $69.83 \%$ \\
\hline Total connectivity & 6.9790 & 7.6579 & 10.2688 & 9.3736 & 8.7234 \\
\hline
\end{tabular}

${ }^{*}$ This table has the spillover of the other assets in the network into each of the cryptocurrencies. This measure is directly taken from the forecast error variance decomposition. Where the first value in column a1 corresponds to how much of the forecast error variance for ETH stems from shocks received from other cryptocurrencies, for the subsample a1. This value is $100 \%$ minus the autoregressive term's contribution to forecast error variance. The last row denotes the total connectivity in the network, taken as a sum of the column in decimal values

Table A4. Return connectivity contribution.

\begin{tabular}{|c|c|c|c|c|c|}
\hline Contribution from & a1 & a2 & a3 & $\mathrm{a} 4$ & Full Sample \\
\hline ETH & $15.51 \%$ & $12.34 \%$ & $9.76 \%$ & $11.11 \%$ & $12.31 \%$ \\
\hline BTC & $14.45 \%$ & $11.60 \%$ & $10.18 \%$ & $11.79 \%$ & $11.90 \%$ \\
\hline LTC & $12.70 \%$ & $10.58 \%$ & $8.85 \%$ & $10.06 \%$ & $10.51 \%$ \\
\hline ETC & $11.49 \%$ & $8.87 \%$ & $8.39 \%$ & $8.47 \%$ & $9.38 \%$ \\
\hline OMG & $7.85 \%$ & $7.99 \%$ & $7.22 \%$ & $4.83 \%$ & $6.98 \%$ \\
\hline DSH & $6.54 \%$ & $8.15 \%$ & $7.80 \%$ & $6.72 \%$ & $7.77 \%$ \\
\hline ZEC & $6.07 \%$ & $9.52 \%$ & $7.00 \%$ & $5.51 \%$ & $7.46 \%$ \\
\hline IOT & $6.08 \%$ & $6.60 \%$ & $7.39 \%$ & $8.23 \%$ & $6.80 \%$ \\
\hline EOS & $5.73 \%$ & $6.42 \%$ & $8.62 \%$ & $7.25 \%$ & $7.21 \%$ \\
\hline XMR & $5.58 \%$ & $9.97 \%$ & $7.84 \%$ & $6.70 \%$ & $7.99 \%$ \\
\hline $\mathrm{BCH}$ & $4.10 \%$ & $2.31 \%$ & $8.34 \%$ & $9.53 \%$ & $4.75 \%$ \\
\hline XRP & $3.90 \%$ & $5.65 \%$ & $8.60 \%$ & $9.81 \%$ & $6.94 \%$ \\
\hline
\end{tabular}

${ }^{*}$ This table has the total contribution of each asset to the total network connectivity, as a percentage term. This is calculated as the total Spillover from each asset divided by the total connectivity measure. 
Table A5. Volatility connectivity contribution.

\begin{tabular}{|c|c|c|c|c|c|}
\hline Contribution from & a1 & a2 & a3 & $\mathrm{a} 4$ & Full Sample \\
\hline ETH & $20.75 \%$ & $12.03 \%$ & $10.04 \%$ & $10.86 \%$ & $13.19 \%$ \\
\hline LTC & $17.14 \%$ & $10.19 \%$ & $9.60 \%$ & $12.32 \%$ & $12.47 \%$ \\
\hline BTC & $14.64 \%$ & $9.43 \%$ & $9.75 \%$ & $12.31 \%$ & $11.87 \%$ \\
\hline OMG & $11.62 \%$ & $6.38 \%$ & $7.16 \%$ & $0.90 \%$ & $5.76 \%$ \\
\hline ETC & $11.70 \%$ & $9.26 \%$ & $9.73 \%$ & $2.80 \%$ & $9.76 \%$ \\
\hline IOT & $4.54 \%$ & $10.68 \%$ & $7.90 \%$ & $9.11 \%$ & $10.02 \%$ \\
\hline DSH & $5.03 \%$ & $3.04 \%$ & $7.01 \%$ & $10.97 \%$ & $4.56 \%$ \\
\hline EOS & $4.79 \%$ & $8.35 \%$ & $8.07 \%$ & $6.29 \%$ & $7.95 \%$ \\
\hline $\mathrm{BCH}$ & $3.77 \%$ & $2.95 \%$ & $8.63 \%$ & $11.64 \%$ & $4.18 \%$ \\
\hline ZEC & $2.32 \%$ & $9.83 \%$ & $5.78 \%$ & $5.50 \%$ & $6.60 \%$ \\
\hline XMR & $2.19 \%$ & $12.35 \%$ & $8.22 \%$ & $7.42 \%$ & $8.27 \%$ \\
\hline XRP & $1.51 \%$ & $5.51 \%$ & $8.12 \%$ & $9.88 \%$ & $5.37 \%$ \\
\hline
\end{tabular}

${ }^{*}$ This table has the total contribution of each asset to the total network connectivity, as a percentage term. This is calculated as the total Spillover from each asset divided by the total connectivity measure.

Table A6. Volatility spillovers between cryptocurrencies.

\begin{tabular}{|c|c|c|c|c|c|}
\hline To & a1 & a2 & a3 & a4 & Full Sample \\
\hline ETH & $67.77 \%$ & $66.58 \%$ & $84.13 \%$ & $70.74 \%$ & $68.73 \%$ \\
\hline LTC & $64.05 \%$ & $65.77 \%$ & $83.13 \%$ & $73.11 \%$ & $67.79 \%$ \\
\hline BTC & $60.70 \%$ & $61.02 \%$ & $83.09 \%$ & $73.20 \%$ & $66.25 \%$ \\
\hline OMG & $56.57 \%$ & $56.13 \%$ & $79.11 \%$ & $17.12 \%$ & $50.29 \%$ \\
\hline ETC & $55.84 \%$ & $58.84 \%$ & $82.90 \%$ & $39.39 \%$ & $61.60 \%$ \\
\hline IOT & $34.73 \%$ & $68.45 \%$ & $75.06 \%$ & $67.09 \%$ & $61.31 \%$ \\
\hline DSH & $34.54 \%$ & $28.67 \%$ & $81.36 \%$ & $70.71 \%$ & $43.72 \%$ \\
\hline EOS & $34.54 \%$ & $56.37 \%$ & $81.50 \%$ & $58.92 \%$ & $56.93 \%$ \\
\hline $\mathrm{BCH}$ & $30.97 \%$ & $36.11 \%$ & $81.64 \%$ & $71.61 \%$ & $41.55 \%$ \\
\hline ZEC & $19.77 \%$ & $65.38 \%$ & $76.26 \%$ & $56.48 \%$ & $52.32 \%$ \\
\hline XMR & $18.41 \%$ & $68.29 \%$ & $82.06 \%$ & $63.32 \%$ & $57.78 \%$ \\
\hline XRP & $13.72 \%$ & $67.59 \%$ & $82.12 \%$ & $68.80 \%$ & $55.78 \%$ \\
\hline Total connectivity & 4.9161 & 6.9921 & 9.7235 & 7.3049 & 6.8404 \\
\hline
\end{tabular}

*This table has the spillover of the other assets in the network into each of the cryptocurrencies. This measure is directly taken from the forecast error variance decomposition. Where the first value in column a1 corresponds to how much of the forecast error variance for ETH stems from schocks received from other cryptocurrencies, for the subsample a1. This value is $100 \%$ minus the autoregressive term's contribution to forecast error variance. The last row denotes the total connectivity in the network, taken as a sum of the column in decimal values. 


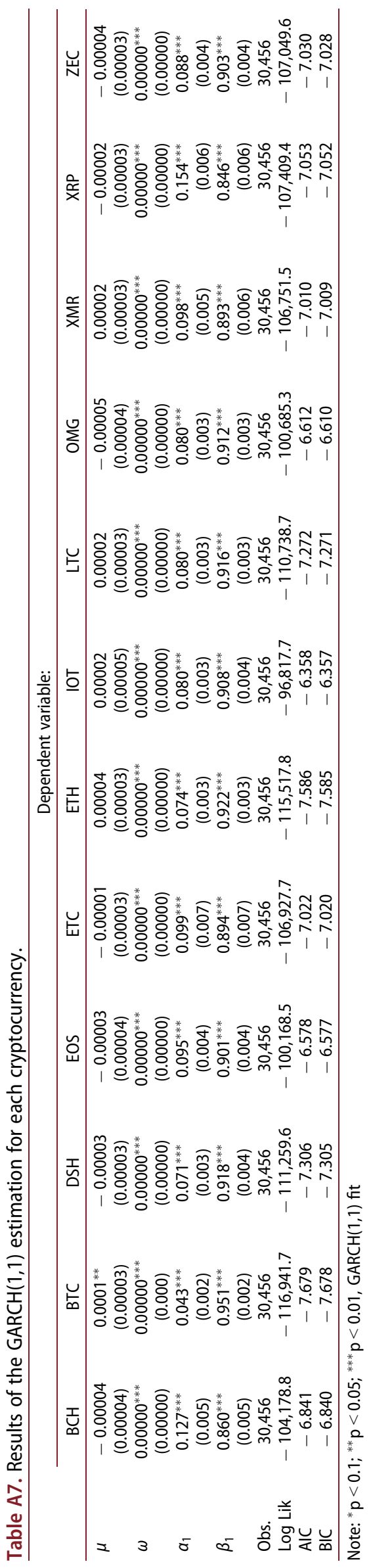


Table A8. Robustness check (GARCH(1,1) filtered).

\begin{tabular}{llccc}
\hline & \multicolumn{3}{c}{ Percentage of connectivity to } \\
\cline { 2 - 4 } & Baseline & GARCH & p10 & GARCH p10 \\
\hline ETH & $9.14100616 \%$ & $9.14100554 \%$ & $9.13991833 \%$ & $9.13991623 \%$ \\
BTC & $9.10613081 \%$ & $9.10612992 \%$ & $9.10324558 \%$ & $9.10324136 \%$ \\
LTC & $8.87885827 \%$ & $8.87885772 \%$ & $8.87504954 \%$ & $8.87504501 \%$ \\
ETC & $8.66989635 \%$ & $8.66989499 \%$ & $8.66832182 \%$ & $8.66831745 \%$ \\
XMR & $8.38062602 \%$ & $8.38062333 \%$ & $8.37407961 \%$ & $8.37407272 \%$ \\
DSH & $8.35278031 \%$ & $8.35277484 \%$ & $8.34062651 \%$ & $8.34061375 \%$ \\
ZEC & $8.23885934 \%$ & $8.23885606 \%$ & $8.23185114 \%$ & $8.23184259 \%$ \\
EOS & $8.10026349 \%$ & $8.10026362 \%$ & $8.10163271 \%$ & $8.10162879 \%$ \\
OMG & $8.06950173 \%$ & $8.06949951 \%$ & $8.07067954 \%$ & $8.07067394 \%$ \\
XRP & $8.00493717 \%$ & $8.00493746 \%$ & $8.00677706 \%$ & $8.00677922 \%$ \\
IOT & $7.97147828 \%$ & $7.97147715 \%$ & $7.9689369 \%$ & $7.96893101 \%$ \\
BCH & $7.08566206 \%$ & $7.08566127 \%$ & $7.09785709 \%$ & $7.09784957 \%$ \\
Total & 8.72342375 & 8.72342213 & 8.72158972 & 8.72158412 \\
\hline
\end{tabular}

*Robustness check spillover: Contribution to each cryptocurrency.

Table A9. Robustness check (GARCH(1,1) filtered).

\begin{tabular}{lcccc}
\hline & \multicolumn{3}{c}{ Percentage of connectivity from } \\
\cline { 2 - 5 } & Baseline & GARCH & p10 & GARCH p10 \\
\hline ETH & $12.3099114 \%$ & $12.3099038 \%$ & $12.2917709 \%$ & $12.2917562 \%$ \\
BTC & $11.8982463 \%$ & $11.8982534 \%$ & $11.9119895 \%$ & $11.911995 \%$ \\
LTC & $10.5059337 \%$ & $10.5059273 \%$ & $10.4703189 \%$ & $10.4702954 \%$ \\
ETC & $9.38407162 \%$ & $9.38406749 \%$ & $9.37798389 \%$ & $9.37797417 \%$ \\
XMR & $7.99145995 \%$ & $7.99145822 \%$ & $7.98262959 \%$ & $7.98263332 \%$ \\
DSH & $7.77393279 \%$ & $7.77393076 \%$ & $7.7792921 \%$ & $7.77928949 \%$ \\
ZEC & $7.45702134 \%$ & $7.45701924 \%$ & $7.46435939 \%$ & $7.46435688 \%$ \\
EOS & $7.20931641 \%$ & $7.20931617 \%$ & $7.2014107 \%$ & $7.20140582 \%$ \\
OMG & $6.98246031 \%$ & $6.98245713 \%$ & $6.99462789 \%$ & $6.99462289 \%$ \\
XRP & $6.94230218 \%$ & $6.94230368 \%$ & $6.94425646 \%$ & $6.94426303 \%$ \\
IOT & $6.79830402 \%$ & $6.798304 \%$ & $6.78666614 \%$ & $6.78665961 \%$ \\
BCH & $4.74703988 \%$ & $4.74704023 \%$ & $4.77367034 \%$ & $4.77365988 \%$ \\
Total & 8.72342375 & 8.72342213 & 8.72158972 & 8.72158412 \\
\hline
\end{tabular}

*Robustness check spillover: Contribution from each cryptocurrency. 